\title{
Design and Simulation of a Solar Tracking System for Optimum Energy Absorption
}

\author{
Hussain A. Attia*, Beza Negash Getu \\ Electronics and Communications Engineering Department, American University of Ras Al Khaimah, UAE
}

\begin{abstract}
Nowadays the importance and dependence on solar power source is remarkably increasing as there is a strong need to have clean, cheap and renewable energy compared with other types of energy sources. In this paper, we present a complete design and analysis of an electronic circuit that can be used for optimum solar energy absorption and tracking. The proposed electronic circuit will accurately track the sun light and face the solar panel in the direction of maximum solar energy absorption. The presented design starts with an array of light intensity photo sensors (Light Dependent Resistor (LDR)) followed by a number of processing steps to finally deliver a suitable dc voltage for driving a dc motor, which is required to move and align the solar panel to the direction of maximum solar intensity. There is a continuous controlling and tracking functions using the light intensity information from the three photo sensors. The presented design is implemented using an Op-Amp and general purpose electronic components without a requirement to any special purpose electronic item for tracking. The design also provides an ability of monitoring the various stages using a number of LEDs distributed along the parts of the electronic circuit.
\end{abstract}

Keywords: Solar energy; Light dependent resistor; maximum power point tracker; Op-Amp; CMOS; drive circuit; DC Motor

\section{Introduction}

Recently there is a strong interest and attention in a solar energy compared with other non-renewable energy sources. Solar energy is environmentally clean, abundantly available, cheap, and easily transferrable to other forms of energy [1], [2], [3]. One practical application of solar energy is for use in solar panels as a source of electricity. The level of solar energy absorption can be increased by adjusting the surface of the solar panel in the direction of sun light during full day timing [4], [5]. This is achieved through careful tracking of the movement of the sun during the full day timing at any location of interest. The total number of used solar cells and/or solar panels is the main parameter that determines the cost of any solar generation power system. Tracking system plays a major role to minimize the number of solar panels that are used to generate a solar energy in solar power generation systems compared with a system without a tracker and delivering the same output power. A carefully designed tracking system can guarantee maximum solar power absorption by tracking

*Corresponding author.

E-mail: hattia@aurak.ae

(C) 2014 International Association for Sharing Knowledge and Sustainability

DOI: 10.5383 ijtee.08.01.003 directional movement of the sunlight at all moments of the full working day leading to ensure maximum power output from the PV cells. The sunlight's angle of incidence needs to be constantly perpendicular to the solar panel in order the direct sunlight is always focused on the PV cells [6].

In this paper, a new designed electronic tracking system will be presented. Fig. 1 shows the complete block diagram consisting of the various stages and modules of the system. It is a closed loop controlled tracking system.

The tracker electronic system is dependent on commonly available integrate circuits such as operational amplifiers (IC741 type) and digital chips such as CMOS NOT gates, and AND gates. In addition there are general purpose electronic components such as NPN transistors, diodes, LEDs and Relays. So, the target for the system is to attain a reliable closed loop controlled tracking with simple complexity. The tracker acquires information about the instantaneous levels of sunlight intensity from the three sensors, analyzes the data, drives the dc motor and then adjusts the position of the panel towards the sensor with maximum sunlight energy absorption. 


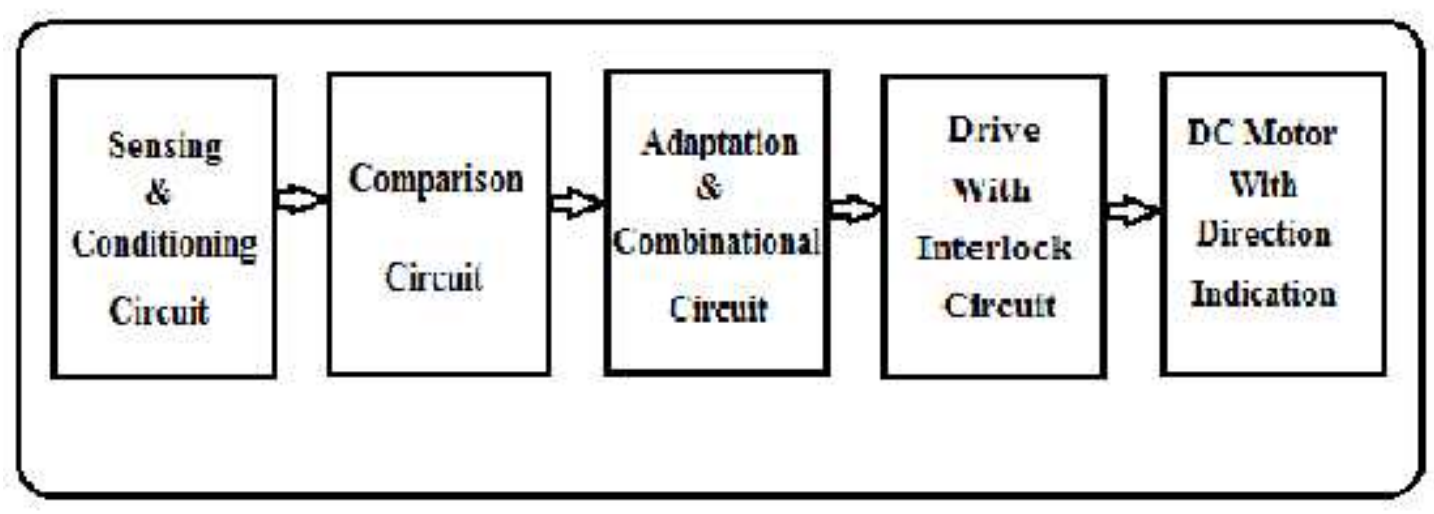

Fig. 1. Block Diagram of the proposed Solar Tracker

\section{Sensing and Conditioning Circuit}

The proposed design started by using three Cadmium Sulfide (CdS) photo resistors that are used for sensing the light intensity. The CdS photo resistor is a light dependent resistor (LDR) [5], [7]. The LDR is a resistor with a certain range of resistance depending inversely on the intensity of light. The range of resistance varies between $10 \mathrm{k}$ in case when the LDR is in direct line of sight with sunlight or in full light conditions, and with value of $100 \mathrm{~K}$ in dark conditions. So, it works as a variable resistor controlled by light intensity. Fig. 2 shows the shape and the characteristics of selected LDR [8].

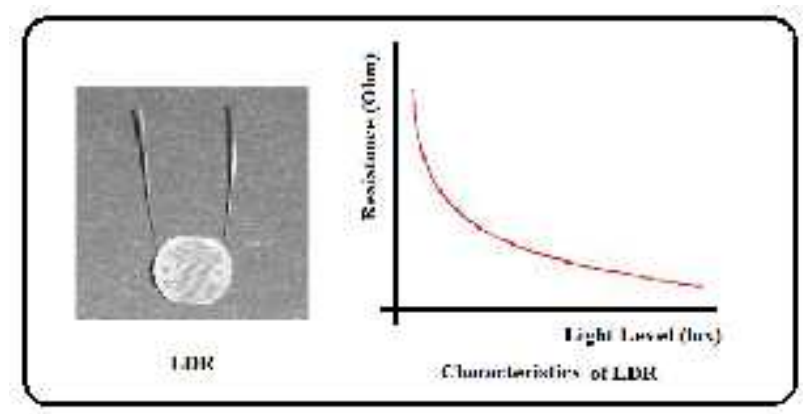

Fig. 2. LDR with Characteristics

The three photo resistors are designed to be fixed on the surface of the solar panel according to the angular orientation shown in Fig. 3 with very small equal angular spacing between them so as to sense the sunlight with accurate accuracy. The Left (L), Middle (M) and Right (R) sensors are fixed in such way that the middle LDR is always to be directed to the maximum sun light intensity after the tracking process is accomplished. At any instant of time, the left or the right sensor may indicate maximum sun light energy absorption and accordingly the motor will drive the panel to the left or to the right so that the middle sensor takes over the position of the sensor with the maximum sun light intensity absorption.

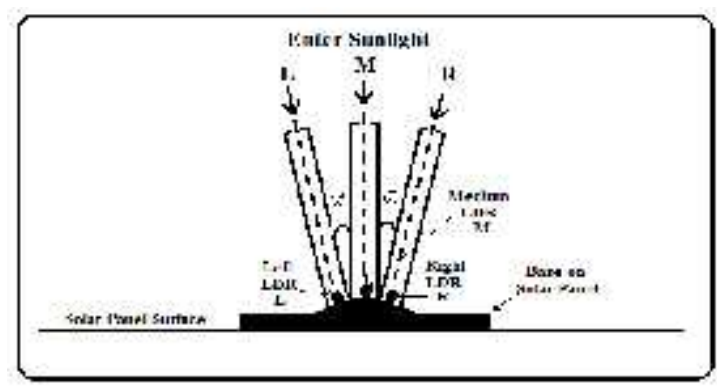

Fig. 3. Orientation of the 3 LDRs on solar panel surface

The resistance value of LDRs will change in the range between $10 \mathrm{~K}$ to $100 \mathrm{~K}$ inversely with the intensity of sunlight. The sensor output is read as a certain dc level of voltage in accordance with sunlight intensity. For the overall purpose of the sensing, we have a $10 \mathrm{~K}$ fixed serial resistor connected in series with the LDR. The output of the $10 \mathrm{~K}$ resistor will be a maximum value of $5 \mathrm{~V}$ when the LDR is in full light condition and $0.9 \mathrm{~V}$ at LDR equal $100 \mathrm{~K}$ in dark condition. Fig. 4 shows the sensor module of the tracker circuit including the connection of the three LDRs with fixed serial resistors.

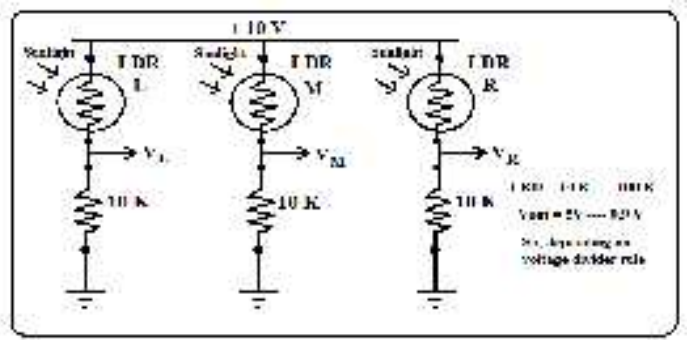

Fig. 4. The sensor circuit with the connection of the LDRs

This design was constructed and simulated using the National Instruments (NI) MultiSim simulation software program that is suitable for electronic circuit design and testing with the ability and flexibility of providing a database library with huge number of electrical and electronic components [9]. As shown in Fig. 4, the combination of each LDR with serial resistor acts overall like a variable resistor and provides the required $\mathrm{dc}$ voltage ranges of the sensing circuit. 


\section{Comparison Circuit}

From the previous section, the sunlight intensity absorbed by the three sensors is transduced to appropriate dc voltages using LDR. The sensor voltages will be fed to appropriate comparator circuits in order to produce appropriate logic values for next stage processing. Three operational amplifiers of type IC741 are selected to make comparisons on the amount of sunlight intensity absorbed by the left, the middle and the right sensors. The positive input of the first op-amp is the voltage of the right LDR (Vright) and the negative input of the op-amp is the voltage of the middle LDR (Vmiddle). The probability of the output results in this operational amplifier is one of the following: $\left(V_{R}>V_{M}\right.$ )$,\left(V_{M}>V_{R}\right),\left(V_{R}=V_{M}\right)$. In the first case the output voltage of op-amp is (+Vcc), in second case the output voltage is $(-\mathrm{Vcc})$ and the output of op-amp in third case is $(0 \mathrm{~V})$. Fig. 5 shows the connection of the IC741 to receive $V_{R}$, and $V_{M}$ and deliver Vout with one of the following values $+\mathrm{Vcc}, 0 \mathrm{~V}$, or $-\mathrm{Vcc}$. The same procedure is repeated for the second and the third opamp in order to cover all possible sensor voltage comparisons. The results of the voltage comparisons for the second op-amp are $\left(V_{R}>V_{L}\right),\left(V_{L}>V_{R}\right),\left(V_{R}=V_{L}\right)$ and the results of comparisons of the third op-amp is one of the following: $\left(V_{L}>V_{M}\right),\left(V_{M}>V_{L}\right),\left(V_{L}=V_{M}\right)$.

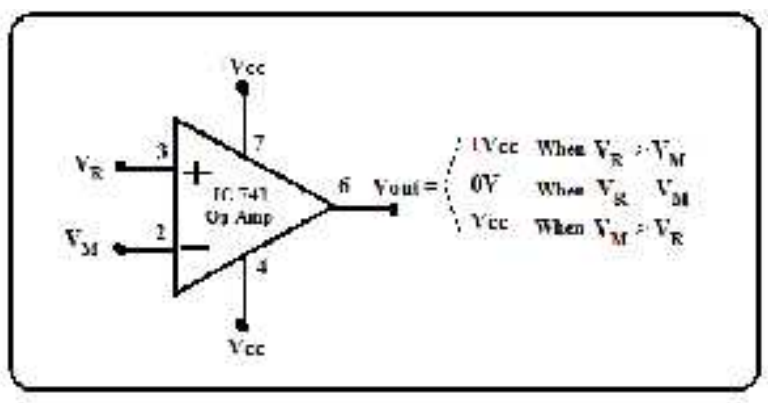

Fig. 5. The op-amp connection for the first comparison circuit

\section{Adaptation and Combinational Circuit}

The function of this circuit is to deliver one of the two logic levels, which are either High level $(10 \mathrm{~V})$ when the received voltage from the output of the op-amp is equal to $+\mathrm{Vcc}$, or Low level $(0 \mathrm{~V})$ when the received voltage from the output of op-amp is equal to $-\mathrm{Vcc}$ or $0 \mathrm{~V}$. The designed circuit includes two successive NOT gates (Schmitt trigger) to change the distorted incoming signal to a clear and stable high or low voltage level and to reduce the effects of noise on the line [7]. This adaptation and combinational circuit has three parts one for each op-amp line and there are two LEDs in each part to have two different indications related to the input voltages of the op-amp. The total number of used NOT gates is equal the total number of LEDs which is 6 components in total. The last part included in this circuit represents a certain logic combination designed to give a suitable logic command for the motor drive circuit so that the motor performs the desired motion of the solar panel and stops when the position of the solar panel is normal to sun light intensity for maximum light absorption. The logical combinations required for an input to the driving circuit are constructed from two AND gates with additional LED for each gate to give indication of the output of the AND gates. Fig. 7 represents the proposed adaptation \& combinational electronic circuit and Table 1 explains all probabilities of op-amps outputs simulated using the NI Multisim program as well as logic level indications. Fig. 8 shows all probability of op-amps outputs that may happen generally whereas Table 2 shows the suitable logic states that may happen at the same time. The truth table logical outputs shown in Table 2 (GL and GR) are constructed by assuming that the movements of the panel are with respect to the middle sensor of the solar panel, which is firstly towards the high intensity sunlight direction. The logical functions of GL and GR refer to movements of the solar panel to the left and the right depending on the intensity of light absorption. The logic minimization by K-maps [10] and related logic functions for solar panel Right Movement, Left Movement, and Stop or No Movement are illustrated in Fig. 9.

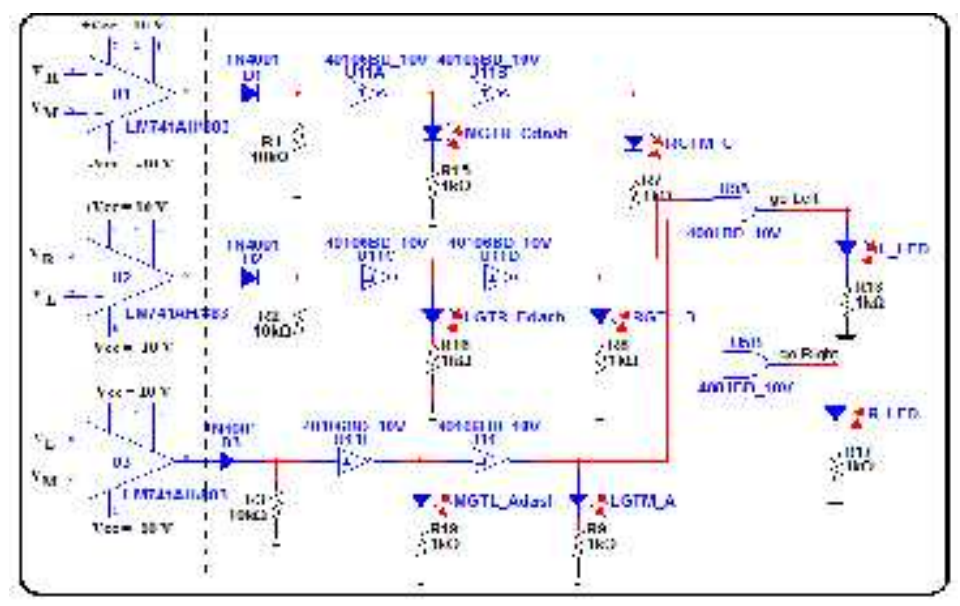

Fig. 7. Adaptation \& Combinational Circuit 
Table 1. All Probabilities of digital outputs for the adaptation and combinational circuit

\begin{tabular}{|c|c|c|c|c|}
\hline $\begin{array}{l}\text { Op- } \\
\text { Amp }\end{array}$ & $\begin{array}{c}1^{\text {st }} \\
\text { State }\end{array}$ & $\begin{array}{l}\text { LEDs } \\
\text { State } \\
\end{array}$ & $\begin{array}{l}2^{\text {nd }}, 3^{\text {rd }} \\
\text { States }\end{array}$ & LEDs State \\
\hline $\begin{array}{l}1^{\text {st }} \mathrm{Op}- \\
\text { amp } \\
(\mathrm{R}, \mathrm{M})\end{array}$ & $\mathrm{R}>\mathrm{M}$ & $\begin{array}{c}1^{\text {st }} \text { LED }= \\
0 \\
2^{\text {nd }} L E D= \\
1\end{array}$ & $\begin{array}{l}\mathrm{R}<\mathrm{M}, \\
\mathrm{R}=\mathrm{M}\end{array}$ & $\begin{array}{c}1^{\text {st }} \text { LED }= \\
1 \\
2^{\text {nd }} \text { LED }= \\
0\end{array}$ \\
\hline $\begin{array}{l}2^{\text {nd }} \mathrm{Op}- \\
\text { amp } \\
(\mathrm{R}, \mathrm{L})\end{array}$ & $\mathrm{R}>\mathrm{L}$ & $\begin{array}{c}1^{\text {st }} \text { LED }= \\
0 \\
2^{\text {nd }} L E D= \\
1\end{array}$ & $\begin{array}{c}\mathrm{R}<\mathrm{L}, \\
\mathrm{R}=\mathrm{L}\end{array}$ & $\begin{array}{c}1^{\text {st }} \text { LED }= \\
1 \\
2^{\text {nd }} L E D= \\
0\end{array}$ \\
\hline $\begin{array}{l}3^{\text {rd }} \text { Op- } \\
\text { amp } \\
(\mathrm{L}, \mathrm{M})\end{array}$ & $\mathrm{L}>\mathrm{M}$ & $\begin{array}{c}1^{\text {st }} \text { LED }= \\
0 \\
2^{\text {nd }} \text { LED }= \\
1\end{array}$ & $\begin{array}{l}\mathrm{L}<\mathrm{M}, \\
\mathrm{L}=\mathrm{M}\end{array}$ & $\begin{array}{c}1^{\text {st }} \text { LED }= \\
1 \\
2^{\text {nd }} \text { LED }= \\
0\end{array}$ \\
\hline
\end{tabular}

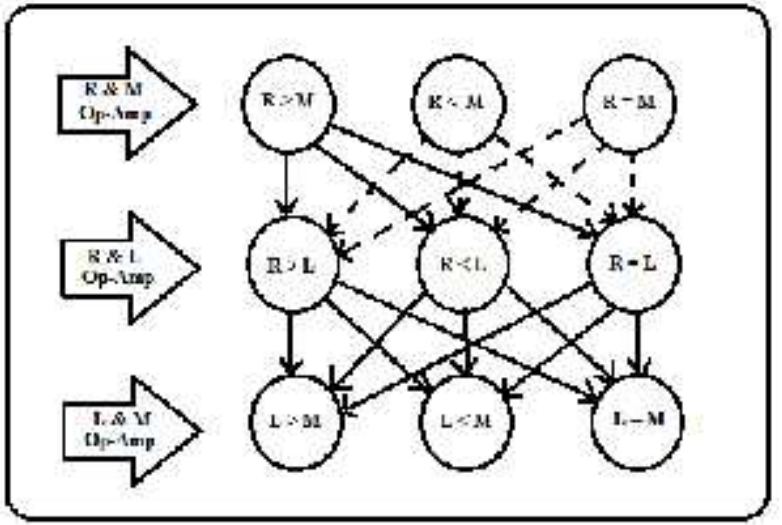

Fig. 8. All possible logical combinations of op-amps states

Table 2. Truth table for all possible logic states

\begin{tabular}{|c|c|c|c|c|c|}
\hline $\begin{array}{c}\mathrm{A} \\
\mathrm{R}>\mathrm{M}\end{array}$ & $\begin{array}{c}\text { B } \\
\mathrm{R}>\mathrm{L}\end{array}$ & $\begin{array}{c}\mathrm{C} \\
\mathrm{L}>\mathrm{M}\end{array}$ & $\begin{array}{c}\text { GL } \\
\text { Go } \\
\text { Left }\end{array}$ & $\begin{array}{c}\text { GR } \\
\text { Go } \\
\text { Right }\end{array}$ & Comments \\
\hline 0 & 0 & 0 & 0 & 0 & No Motion \\
\hline 0 & 0 & 1 & 1 & 0 & $\begin{array}{l}\text { Go to left } \\
\text { direction }\end{array}$ \\
\hline 0 & 1 & 0 & 0 & 0 & No Motion \\
\hline 0 & 1 & 1 & 0 & 0 & \multirow{2}{*}{$\begin{array}{l}\text { Not logic } \\
\text { to happen }\end{array}$} \\
\hline 1 & 0 & 0 & 0 & 0 & \\
\hline 1 & 0 & 1 & 1 & 0 & $\begin{array}{l}\text { Go to left } \\
\text { direction }\end{array}$ \\
\hline 1 & 1 & 0 & 0 & 1 & $\begin{array}{l}\text { Go to right } \\
\text { direction }\end{array}$ \\
\hline 1 & 1 & 1 & 0 & 1 & $\begin{array}{c}\text { Go to right } \\
\text { direction }\end{array}$ \\
\hline
\end{tabular}

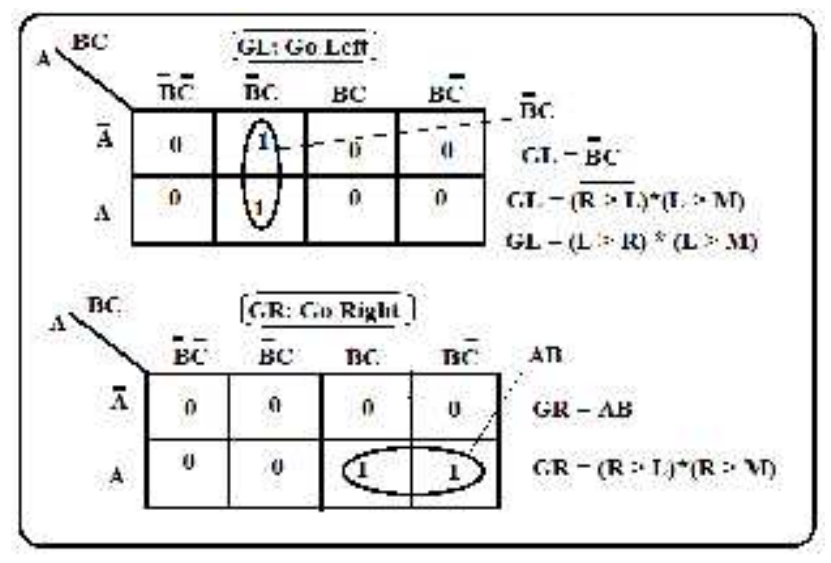

Fig. 9. K - Maps for left movement $(G L=1)$, right movements $(\mathbf{G R}=\mathbf{1})$ and or stop conditions $(\mathbf{G L}=\mathbf{G R}=\mathbf{0})$ of the solar panel.

\section{Drive with Interlock Circuit}

The function of this circuit is to drive the last stage (dc load) of the proposed design by supplying dc voltage with appropriate polarity to suitably designed dc motor that is used to rotate the mechanical system responsible for the solar panel motion toward maximum power point absorption. The decision of doing the motion of the solar panel comes from the logical combinations of the outputs of the previous driving circuit.

Firstly, in the case when the solar panel is normal to direct sunlight, it will lead to $\left(\mathrm{V}_{\mathrm{R}}<\mathrm{V}_{\mathrm{M}}\right)$ and $\left(\mathrm{V}_{\mathrm{L}}<\mathrm{V}_{\mathrm{M}}\right)$. Hence these conditions mean that the outputs of logic combinations will be (go Left $=0$, go Right $=0$ ) then Q1 (2N2222) and Q3 (2N2222) together in Cut Off, so there is no motion to either left or right; LEDs (Move Left LED, and Move Right LED) are in OFF state as well as connected relays for the two motions are also in OFF state in this case. The two other transistors Q2 (2N2222), and Q4 (2N2222) are placed for safety in practical usage and are responsible for interlocking between the two different motions (Left Motion, Right Motion). In the above case of OFF state, when the two logic commands for motion are logic (0), Q2 and Q4 are in Cut Off and that means no effect for them in this case.

Secondly, when the direction of solar panel is misaligned from normal sunlight, the logic commands will be either (go Left, GL=1) or (go Right, GR=1) depending on the instantaneous sensor output voltages $\left(\mathrm{V}_{\mathrm{R}}, \mathrm{V}_{\mathrm{M}}, \mathrm{V}_{\mathrm{L}}\right)$ that represent analog voltage values proportional to the instantaneous intensity of sunlight. In the case when the voltage of right photo sensor (Right LDR) is the biggest value, the logic commands become (go Right $=1$, go Left $=0$ ) and this will drive the right relays (Relay1_Right, Relay2_Right) to become in the ON state while the left relays (Relay1_Left, Relay2_Left) is in the OFF state. In this state, the transistor Q2 is ON since it is driven by go Right command and on the other side Q4 is OFF, so there is no any chance in practical testing the two direction relays (go left and go right) work at the same time, and this is 
important to avoid any electrical short circuit of the supply that is used to drive the related dc load in the last stage.

The addition of the interlock circuit part will be important in the cases when the proposed solar tracking circuit is used in certain regions that have a certain level of electromagnetic noise. Noise can negatively affect the functional quality of any electronic circuit and for this case and to avoid any chance of the two logic commands (go Left, go Right) occurring high at the same time, the designed interlock circuit represented by Q2, Q4 will reset the related drive transistors Q1 and Q3.

Fig. 10 represents the proposed electronic circuit that performs the drive and interlock function and Figure 11 shows the relay connections to deliver a certain required dc voltage with suitable polarity to the connected dc load or motor.

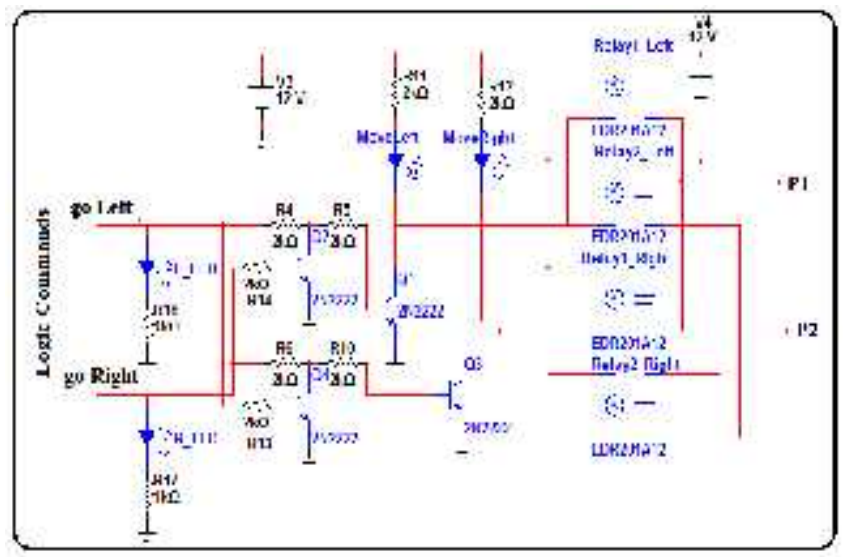

Fig. 10: The drive with interlock circuit

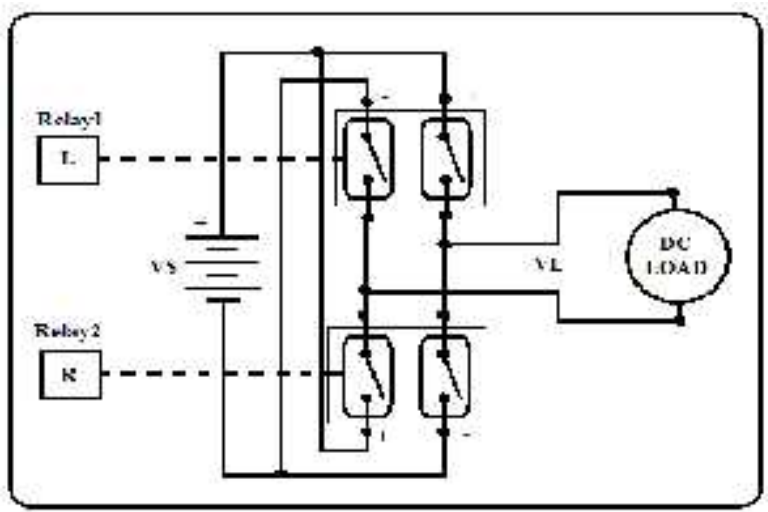

Fig. 11. The go left and go right relay connections

\section{DC Motor with Direction Indication}

This circuit represents a dc load (represented by a certain type of dc motor) and it is the last part of the electronic circuit for the tracking system. A suitable type dc motor will be used to drive the mechanical system that rotates the solar panel base and align the solar panel with maximum point of solar energy absorption. The power rating of the motor depends on the dimensions and weight of the solar panel. In the case of using large size and heavy weight dimension solar panels, appropriate relays and $\mathrm{dc}$ motor with suitable specifications need to be selected to move the big size mechanical system. The circuit includes two indicators working separately; each one for a specific polarity of dc load supply voltage. The LEDs are connected together in antiparallel way. There is a serial resistor used to limit the current of the LEDs, the value of this serial resistor R20 ( $1 \mathrm{~K})$ is determined from the related forward voltages and rated current of the LEDs. The forward voltage of LED is equal 1.8 Volt, and the rated current is $12 \mathrm{~mA}$, so the remaining voltage across serial resistor is equal 10.2 Volt since the power supply voltage is 12 Volts. Since the rated current of the LED is $12 \mathrm{~mA}$, the value of the corresponding suitable series resistor is 850

- A standard value $1 \mathrm{~K}$ is selected for the serial resistor and this will lead to the actual maximum current of the LEDs to be $10.2 \mathrm{~mA}$ and it is below the rated current [7], [11], [12], [13]. Fig. 12 illustrates the connection of $\mathrm{dc}$ motor with motion direction indicator LEDs.

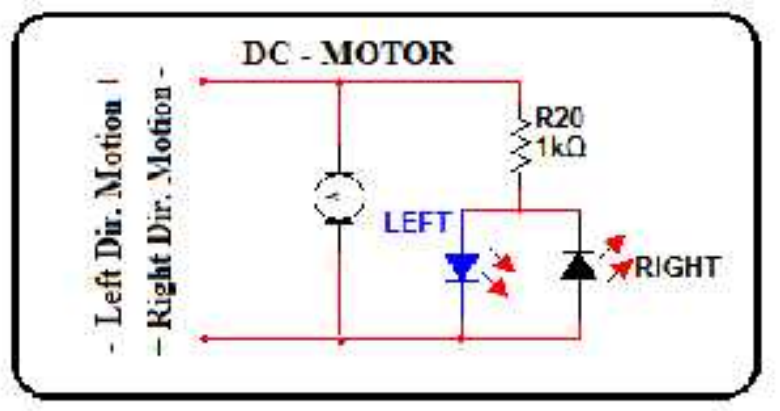

Fig. 12. DC motor with motion direction indicator LEDs

\section{Simulation Results}

National Instruments (NI) MultiSim software offers important and easy to use test and measurement facilities. It offers an opportunity to make integrated testing and provides complete results to evaluate and improve any designed electronic circuit. The complete design of the proposed solar tracking electronic circuit is illustrated in the Fig. 13. The figure includes 9 Voltmeters connected in a suitably distributed test points to have complete monitoring, simulation and analysis of the overall closed loop control circuit. The controlling is achieved through the received analog photo-sensor (LDRs) voltages that are measured by Meter1-VL, Meter2-VM, Meter3-VR; the related measured voltages are from $0.5 \mathrm{~V}$ to $5.0 \mathrm{~V}$. Other group of meters are used to monitor the output logic levels of the successive NOT gates in the three lines; the meters are Meter4 ( $\mathrm{L}>\mathrm{M})$, Meter5 ( $\mathrm{R}>\mathrm{L})$, Meter6 $(\mathrm{R}>\mathrm{M})$. The go right and go left logic commands are delivered by the combinational circuit that is monitored by Meter7 and Meter8. The meters are used to indicate the go Left and go Right states respectively. Meter9 is connected directly across the output dc load to show one of the three directions of the motion of the dc motor: Right direction motion, Left direction motion, or NO motion. 


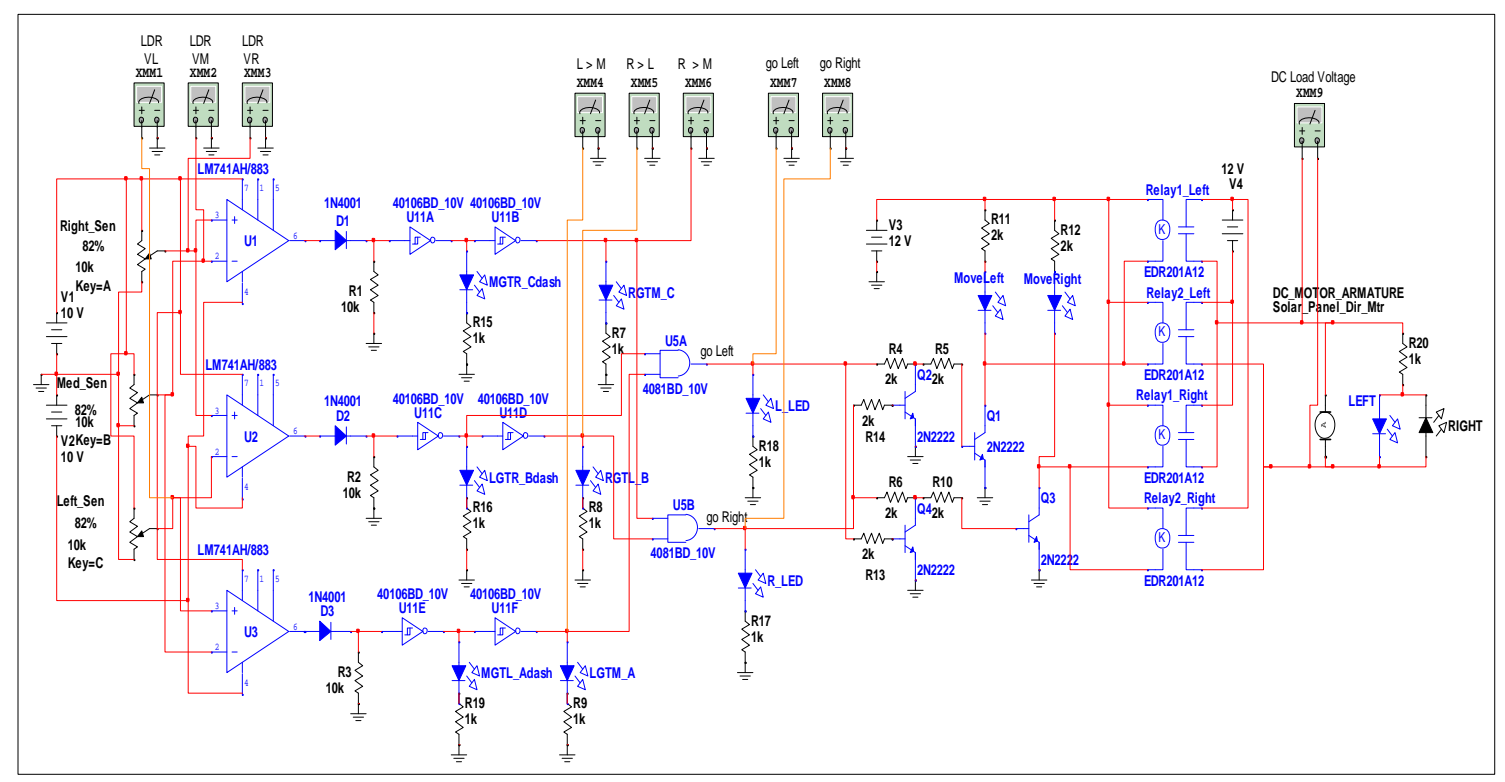

Fig. 13. Complete testing to the proposed tracker System

Table 3. Simulation readings for different cases of sensor analog voltages.

\begin{tabular}{|c|c|c|c|c|c|c|c|c|}
\hline $\begin{array}{l}\text { M1 } \\
\text { VL } \\
\text { (V) }\end{array}$ & $\begin{array}{l}\text { M2 } \\
\text { VM } \\
\text { (V) }\end{array}$ & $\begin{array}{l}\text { M3 } \\
\text { VR } \\
\text { (V) }\end{array}$ & $\begin{array}{c}\text { M4 } \\
\text { L>M } \\
(\mathrm{V})\end{array}$ & $\begin{array}{l}\text { M5 } \\
\text { R>L } \\
\text { (V) }\end{array}$ & $\begin{array}{l}\text { M6 } \\
\text { R> } \\
\text { M } \\
\text { (V) }\end{array}$ & $\begin{array}{c}\text { M7 } \\
\text { Go } \\
\text { L } \\
\text { (V) }\end{array}$ & $\begin{array}{c}\text { M8 } \\
\text { Go } \\
\text { R } \\
\text { (V) }\end{array}$ & $\begin{array}{c}\text { M9 } \\
\text { MTR } \\
\text { (V) }\end{array}$ \\
\hline $\begin{array}{l}8 \% \\
0.78\end{array}$ & $\begin{array}{c}12 \% \\
1.2\end{array}$ & $\begin{array}{l}10 \% \\
0.99\end{array}$ & $0 \mathrm{~V}$ & $10 \mathrm{~V}$ & $0 \mathrm{~V}$ & $0 \mathrm{~V}$ & $0 \mathrm{~V}$ & $0 \mathrm{~V}$ \\
\hline $\begin{array}{l}8 \% \\
0.78\end{array}$ & $\begin{array}{c}12 \% \\
1.2\end{array}$ & $\begin{array}{c}12 \% \\
1.2\end{array}$ & $0 \mathrm{~V}$ & $10 \mathrm{~V}$ & $0 \mathrm{~V}$ & $0 \mathrm{~V}$ & $0 \mathrm{~V}$ & $0 \mathrm{~V}$ \\
\hline $\begin{array}{l}8 \% \\
0.78\end{array}$ & $\begin{array}{c}12 \% \\
1.2\end{array}$ & $\begin{array}{c}14 \% \\
1.3\end{array}$ & $0 \mathrm{~V}$ & $10 \mathrm{~V}$ & $\begin{array}{l}10 \\
V\end{array}$ & $0 \mathrm{~V}$ & $10 \mathrm{~V}$ & -12 \\
\hline $\begin{array}{c}12 \% \\
1.2\end{array}$ & $\begin{array}{c}12 \% \\
1.2\end{array}$ & $\begin{array}{c}8 \% \\
0.78\end{array}$ & $0 \mathrm{~V}$ & $0 \mathrm{~V}$ & $0 \mathrm{~V}$ & $0 \mathrm{~V}$ & $0 \mathrm{~V}$ & $0 \mathrm{~V}$ \\
\hline $\begin{array}{l}13 \% \\
1.28\end{array}$ & $\begin{array}{c}12 \% \\
1.2\end{array}$ & $\begin{array}{c}8 \% \\
0.78\end{array}$ & $10 \mathrm{~V}$ & 0 & 0 & 10 & 0 & +12 \\
\hline $\begin{array}{l}40 \% \\
3.98\end{array}$ & $\begin{array}{l}40 \% \\
3.98\end{array}$ & $\begin{array}{l}40 \% \\
3.98\end{array}$ & $0 \mathrm{~V}$ & $10 \mathrm{~V}$ & $0 \mathrm{~V}$ & $0 \mathrm{~V}$ & $0 \mathrm{~V}$ & $0 \mathrm{~V}$ \\
\hline $\begin{array}{l}44 \% \\
4.38\end{array}$ & $\begin{array}{l}40 \% \\
3.98\end{array}$ & $\begin{array}{l}42 \% \\
4.20\end{array}$ & $10 \mathrm{~V}$ & $0 \mathrm{~V}$ & $\begin{array}{l}10 \\
V\end{array}$ & $10 \mathrm{~V}$ & $0 \mathrm{~V}$ & +12 \\
\hline $\begin{array}{l}44 \% \\
4.38\end{array}$ & $\begin{array}{l}42 \% \\
4.20\end{array}$ & $\begin{array}{l}46 \% \\
4.59\end{array}$ & $10 \mathrm{~V}$ & $10 \mathrm{~V}$ & $\begin{array}{l}10 \\
\mathrm{~V}\end{array}$ & $0 \mathrm{~V}$ & $10 \mathrm{~V}$ & -12 \\
\hline $\begin{array}{l}46 \% \\
4.59\end{array}$ & $\begin{array}{l}42 \% \\
4.20\end{array}$ & $\begin{array}{l}46 \% \\
4.59\end{array}$ & $10 \mathrm{~V}$ & $10 \mathrm{~V}$ & $\begin{array}{l}10 \\
V\end{array}$ & $0 \mathrm{~V}$ & $10 \mathrm{~V}$ & -12 \\
\hline $\begin{array}{l}50 \% \\
4.99\end{array}$ & $\begin{array}{l}50 \% \\
4.99\end{array}$ & $\begin{array}{l}50 \% \\
4.99\end{array}$ & $0 \mathrm{~V}$ & $10 \mathrm{~V}$ & $0 \mathrm{~V}$ & $0 \mathrm{~V}$ & $0 \mathrm{~V}$ & $0 \mathrm{~V}$ \\
\hline
\end{tabular}

Table 3 shows the simulation readings of the nine meters for the various cases of sensor analogue voltages for the solar tracker circuit. The first three columns represent the various probabilities of output voltages of the photo sensors proportional with the instantaneous sunlight intensity. The analog voltages will be used as input for the next stage of the tracker circuit and the voltages represent the light intensity of the three photo sensors separated by small angular spacing. The readings of the three logic data $(\mathrm{L}>\mathrm{M}, \mathrm{R}>\mathrm{L}, \mathrm{R}>\mathrm{M})$ represent the logic results of the three op-amp comparisons. The readings of the logic commands (GoL, GoR) are the outputs of the combinational logic circuits. The readings of M9 are the dc voltages that are delivered to the dc motor. We can know the direction of motion of the dc motor from the readings of a certain simulation state. For example from the first row, we can understand there is no dc motor motion and hence no movement of solar panel; this is because the middle sensor (LDR) shows maximum instantaneous voltage since the solar panel is in the maximum solar energy absorption position. The case of the second row is also the same (no need of motion) since the left and right sensors aren't showing higher voltage readings. The third row readings show the logic values of $R>M=1, R>L=1, L>M=0$. This means $L<M<R$ and hence the instantaneous voltage from right LDR is highest compared with the other photo sensors. This condition will lead to the logic command $\mathrm{GoR}=1$ and as a result the driving circuit drives the motor to rotate to the right direction. The readings of the fourth row show NO Motion whereas the readings of the fifth row show the motion is in the left direction. The readings shown in the rest of the rows of Table 3 are sensor voltages and logic commands for motion in suitable direction or for state of NO Motion similar to the analysis of the five rows discussed above. The records of all analogue voltages of the photo sensors (Left LDR), (Middle LDR), and (Right LDR) as well as the state of dc motor (half of the voltage across the dc motor) all these data are shown in Fig. 14. 


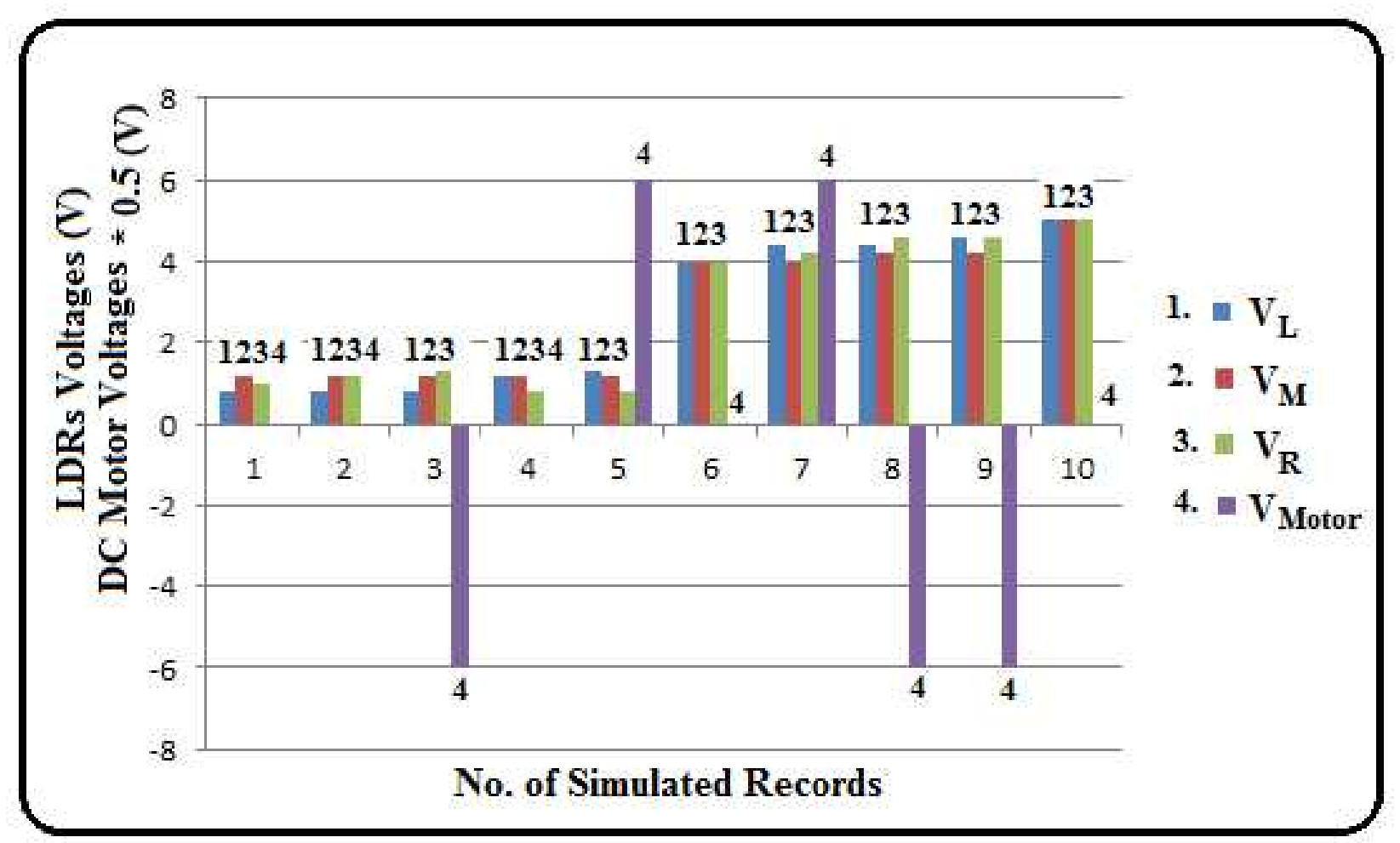

Fig.14. Bar chart of data of simulation records

\section{Conclusions}

This paper proposes a new electronic design suitable to be used for tacking and absorption of optimum solar energy. The following remarks could be the summary of the findings from this work.

- The results of the simulated records are in agreement with the objective of the presented electronic design that represent a closed loop controlled solar tracking system for maximum solar energy absorption. This agreement between the goal of the design and the simulated data also shows the importance of the MultiSim software in the field of electronic design.

- The proposed tracker is implemented using common or general use electrical and electronic components, and consequently this has a major role in simplifying the design and reducing the total cost of constructing the tracking system.

- The presented design is responsible for single axis sun tracking and maximum solar energy absorption in line with the direction of movement of the sun. However, the line of motion is valid for horizontal or vertical direction and hence this gives an opportunity for two copies of the presented design to perform both horizontal and vertical tracking (dual axis).
- The presented design also gives an opportunity to be used for controlling the movement of heavy or big size solar panels arrays after a small modification of the last part of the design. The needed modification is only to replace a high power rated dc motor that will be suitable with the new mechanical system used for bigger size solar panels or arrays of panels.

\section{References}

[1] Y. J. Huang, Member, IAENG, T. C. Kuo, Member, IAENG, C. Y. Chen, C. H. Chang, P. C. Wu, and T. H. $\mathrm{Wu}$, "The Design and mplementation of a Solar Tracking Generating Power System," Engineering Letters, Vol. 17, Issue 4, p252, December 2009.

[2] S. R. Bull, "Renewable energy today and tomorrow," IEEE Proc., vol. 89, no. 8, pp. 1216-1226, 2001.

[3] S. Rahman, "Green power: what is it and where can we find it?" IEEE Power and Energy Magazine, vol. 1, no. 1, pp. 30-37, 2003.

[4] Chiras, D, D, The Homeowner's Guide to Renewable Energy. New society publishers, $2^{\text {nd }}$ ed, July 2011.

[5] Kais I. Abdul-lateef, "A low cost single-axis sun tracker system using PIC microcontroller," Diyala Journal of Engineering Sciences, Vol. 05, No. 01, pp.65-78, June 2012.

[6] Abu Hanieh, A. A, "Automatic Orientation of Solar Photovoltaic Panels," GCREEDER, Amman-Jordan, March $31^{\text {st }}-$ April $2^{\text {nd }} 2009$. 
[7] Owen Bishop, Electronics: A First Course. UK, Elsevier Ltd, Second edition, 2006.

[8] Sinclair I. R, Sensors and Trasducers. UK, Butterworth-Heinemann, 3rd ed, 2001.

[9] NI MutltSIM, http://www.ni.com/multisim/

[10] M. Morris Mano, Michael D. Ciletti, Digital Design. $5^{\text {th }}$ Edition. Prentice Hall, January 2012
[11] Adel S. Sedra, Kenneth C. Smith, Microelectronic Circuits, $6^{\text {th }}$ Edition. Oxford University Press, December 2009.

[12] H.A. Attia, B.N. Getu, H. Ghadban, A.K.A. Mustafa Portable Solar Charger with Controlled Charging Current for Mobile Phone Devices, Int. J. of Thermal \& Environmental Engineering 7 (1), 17-24

[13] H.A. Attia, H.W. Ping, Y. Al-Mashhadany. Design and analysis for high performance synchronized inverter with PWM power control 2013 IEEE Conference on Clean Energy and Technology (CEAT), 265-270 